\title{
Behavioural Features of Various Social Groups on the Internet
}

\author{
Galina I. Gerasimova ${ }^{\#, *}$, Nadezhda Yu. Gavrilova ${ }^{\#}$ and Pavel S. Medvedev ${ }^{\#}$
}

Industrial University of Tyumen, Tyumen, Russian Federation

\begin{abstract}
Objective: The objective of the article is to find an effective model for teaching children using modern educational technologies.

Background: The relevance of the study is that the formation of communication in social networks is determined by the ability to search for strategies for social contacts. In this regard, a significant part of people uses a ready-made communicative model created on a technological basis in social networks. The issue of understanding the general structure of communication in the formation of the social structure of a person in adolescents remains debatable.

Method: The article notes that the operation of social networks is governed by purely technical methods and technologies, which can be considered as prerequisites for the translation of such technologies into the space of social interactions.

Results: The authors show that the possibility of a regulatory impact on adolescent behaviour fully meets the principles of organising network communities with an orientation on each person's individual characteristics.

Conclusion: The use of Internet technologies allows for the growth and timely development of communication technologies for the formation of a balanced personality in a globalised world.
\end{abstract}

Keywords: Internet, information technology, social communication, formation.

\section{INTRODUCTION}

The creator of the World Wide Web, Tim BernersLee, considered accessibility one of its key aspects [1, 2]. It doesn't matter what hardware or software people use, what language they speak, and where they live; their physical and mental abilities are not important the Internet should be accessible to everyone. Indeed, the Internet has significantly changed the lives of many people with disabilities, removing the barriers that such people have had to deal with in the physical world. Learning, chatting, shopping, and more with the spread of the Internet has become much more accessible to everyone. In 1999, the World Wide Web Consortium (W3C), developing common principles and standards for the Internet, released a list of WCAG 1.0 guidelines (Web Content Accessibility Guidelines) aimed at making the World Wide Web accessible to people with physical disabilities [3].

Electronic and Internet technologies, which have been actively used in academic institutions around the world in recent decades, open up new perspectives for people with disabilities. As well as inclusive education, e-Learning allows a disabled person to receive a profession in the most convenient way for himself. To study, only a computer (laptop or tablet) with unlimited Internet access is needed. Distance education for

*Address correspondence to this author at the Industrial University of Tyumen, Tyumen, Russian Federation; Tel: +73452283660;

E-mail: ggerasimova5430@nuos.pro

\#These authors are equally contributed. people with disabilities, especially those with limited mobility, is an interactive environment in which the same program and textbooks are available the same as for other students who are enrolled in full-time, parttime, or evening education. There is the same support from teachers and even more: during working hours, an online curator is always ready to help you on any issue [4-6].

In accordance with international standards, the educational legislation of Russia guarantees the provision of equal education rights for children with disabilities. Regulatory acts developed and adopted in recent years note the need to include all citizens of the Russian Federation. They have reached school age in the educational process, regardless of the presence of special educational needs. In recent years, much attention has been paid to reforming the traditional education system in Russia. One of the most discussed and legislatively reformed aspects of the education system was the problem of effective education of children with disabilities and physically handicapped children, their socialisation and integration into society. Along with this, the question remains open in science and practice: how to organise the educational process in order to realise the educational needs of a child with disabilities fully, so that such a child receives significant social experience, and his participation in the educational process would not affect the decrease in the overall educational level of children with normative development [7].

Currently, in Russia, there are more than 2 million children with disabilities (about $8 \%$ of all children in the 
country), and their number is growing steadily. In the context of the formation of civil society in the Russian Federation, the most promising form of education for children with disabilities in inclusive education. Inclusive education provides for the organisation of the educational process in which all children, regardless of their physical, mental, and other characteristics, are included in the general education system. In the process of working with such children, it is necessary to establish such an interaction in which the occurrence of emotional, semantic, and positional contact occurs [8, 9]. The most significant for the student in classes is his interaction with a teacher. This interaction makes up a specific educational space, filled with special psychological content for each student. Distance learning is becoming an effective means of implementing inclusive education [10].

The article aims to find an effective model for teaching physically handicapped children and children with disabilities on the basis of a comprehensive school using modern educational technologies. To achieve the objective, the tasks of the research were: to analyse the concept and significance of socio-educational integration from a pedagogical point of view; to correlate the concepts that reveal the essence of the information and educational space, to show the dynamics of their development; to develop a model of distance learning for children with disabilities and physically handicapped children; to formulate the main directions of the functioning of a model of distance learning for physically handicapped children and children with disabilities; to determine the necessary resource support, identify the effectiveness parameters of the model of distance learning for physically handicapped children and children with disabilities.

\section{MATERIALS AND METHODS}

To solve the tasks and test the hypothesis, the following theoretical and empirical methods were used: analysis of philosophical, managerial, psychological, pedagogical literature on the research problem; analysis of normative and educational-methodical documentation, study and generalisation of experience on the topic, modelling, observation, studying the products of pedagogical and managerial activities.

Using the generalisation method, after analysing the literature on the problem, the authors concluded that the models for teaching children with disabilities and children with disabilities today are represented by four forms: training in specialised educational institutions, home teaching, inclusive education, integrated training. It is important that as a result of education, the child is able to live independently among people. With the introduction of new educational standards, the general education system is placed in a situation where the system, and not a child, must adapt to the needs and capabilities of everyone, including a physically handicapped child and a disabled child.

The training model reflects the organisation's features of the educational process; in this case, the features of the organisation of training using distance educational technologies. Distance education provides a wide range of services and guarantees the availability of general and additional education to various social groups in accordance with individual capabilities, needs, and abilities. This form of training has several advantages: flexibility, modularity, wide-coverage, adaptability, access to world information resources. To achieve the goals of distance education, the synergistic effect of the interaction of all participants in educational relations is important [11].

In the analysis of managerial literature, the authors found that the educational organisation, providing educational services to handicapped children and children with disabilities chooses a learning model based on its resources and capabilities. In authors' practice, they turned to the concept of integrated education, in which there is a comprehensive training of physically handicapped children and children with disabilities in state-accredited secondary schools, depending on the capabilities of an organisation and students themselves. Modern information and communication technologies for the education of people with disabilities include: traditional types of technologies (computers, web browsers, word processors, electronic boards and mobile phones with built-in accessibility features); assistive technologies (audio phones, screen readers, adaptive keyboards, additional communication devices); accessible media and formats (hypertext language for describing electronic documents HTML, video materials with subtitles, DAISY - a system of accessible digital information and books in this format).

In the system of secondary vocational education in the implementation of educational programs, various educational technologies are used, including distance educational technologies. At the same time, distance learning acts not only as a reliable alternative to traditional education, but also as a unique integration system where students can participate in the 
educational process without being present at classes in an educational institution.

The principles of inclusive education, the initial requirements for the learning process of children with different needs and abilities, include:

- the principle of maximum accessibility of education for everyone with setting goals that are adequate for all students;

- focus on the needs of everyone in the program and the learning process;

- increasing the degree of participation of each student in teaching activities;

- acceptance and respect of individual characteristics of training;

- $\quad$ creating conditions for increasing the success of each student.

The mentioned principles of inclusive education are the basis for the selection (creation) of inclusive education technologies. These technologies introduced by the educational process are designed to increase the level of adaptation of the educational environment to work with various children, thanks to the flexibility of curricula and teaching methods; creation of a student support system; differentiation in working with different groups; use of the necessary material and technical training aids. For all the variety of forms, methods, techniques, and tools in organising the educational process in an inclusive class, some general requirements make it possible to teach different children simultaneously. These include:

1. Variant training programs for students of one class.

2. A minimum of training time for general work with the whole class, the predominance of individual work.

3. Active use of blank methods (distribution of individual tasks of varying degrees of difficulty on separate forms to children).

4. Positive reinforcement of children's learning activities.

5. Taking into account the emotional characteristics of each child.

\section{RESULTS}

The model of distance learning that was developed is built as a single educational space based on partnership interaction (successful child - successful parent - successful teacher) and consists of three units.

1. Information and analytical unit: collecting the necessary documents, analysing the characteristics of the child's development, the level of assimilation of the minimum educational content, limitations associated with the course of a disease; parent education, including online, special information materials, libraries, video libraries; organisation of conditions for productive communication of all participants in educational relations.

2. Practical unit: a combination of home-based and distance learning provided by an educational organisation at the place of residence of a child and the Regional Resource Centre for Distance Learning of the General Service Centre (GSC); interactive communication with parents in the form of a "virtual reception" (skype, email); conducting activities that help parents increase their knowledge of the developmental features of their child.

3. The reflective unit: analysis of the effectiveness of training (a survey, review books, WINDOWS (open book of observations and revelations), assessment sheets, express diagnostics), taking into account the interest and activity of students.

The content of the blocks of the distance learning model for physically handicapped children and children with disabilities is:

- $\quad$ drawing up an individual curriculum, taking into account the combination of distance, homebased and general forms of education (whenever a child is able to attend an educational organisation);

- training teachers, updating the content of correctional-developmental work, adapting the work forms and methods of special education teachers, educators, psychologists and other specialists of an educational centre to the distance learning model;

- $\quad$ psychological support of a family with a child with special educational needs; active interaction with 
this family, increasing the level of pedagogical competence of parents;

- a personality-oriented approach to education (the orientation of the educational process is not only and not so much on educational competencies, but also on the development of a child's personality, his creative potential; providing opportunities for physically handicapped children and children with disabilities to communicate with each other, with peers with normative development, with teachers and other participants in educational relationships).

Classes are determined for each student individually, taking into account the number of classes conducted in full-time and depend on the characteristics of the child's development, in accordance with the recommendations of a psychological, medical, and pedagogical commission (council) of an educational organisation or medical institution at a place of residence. Classes are held individually, at home, remotely (in real and delayed communication). An individual curriculum is accompanied by recommendations on how to work on a computer, a resource map of possible sources of information for work.

The use of distance learning technologies requires a mandatory review (commenting) of students' work as a pedagogical way of correction and development when working on individual curricula. Training involves consultative and corrective work, which is carried out as part of psychological, speech therapy courses. The formation of new types of student activities occurs through the implementation of continuing education programs, forms of extracurricular activities.

Using distance educational technologies, each student can fully master not only basic but also additional educational programs, realise their creative abilities. For students in grades 9-11, courses on preprofile training and psychological orientation have been developed, the purpose of which is professional selfdetermination of students. Another area of distance learning is the identification and development of the creative potential of children and adolescents with disabilities, contributing to their more complete social adaptation in the modern world. To this end, the psychological and pedagogical service is working to diagnose the level of development of children's abilities, identifying individual development programs.
The inclusion of parents in a single educational space through partnership forms and methods of interaction leads to the development of their pedagogical competencies, which helps to improve the quality of education of physically handicapped children and children with disabilities, their level of socialisation. Social adaptation and self-realisation of physically handicapped children and children with disabilities in the "Regional Education Centre" is carried out through a system of additional education and leisure activities. Children and their parents participate (remotely and inperson) in various contests of family creativity, student competitions. The distance learning model provides physically handicapped children and children with disabilities the opportunity to participate in extracurricular projects and exhibition activities on the school's website. In the learning process, children choose objects for research, modelling in accordance with the objectives of the subject.

Technical support is provided by the staff of the distance school in person (visits to municipalities of the Novosibirsk region) and remotely (through remote access programs, video, and audio communications). Technical assistance includes the delivery, installation, and launch of equipment, software, implementation and training of new software, technical advice. At the end of the school year, based on an analysis of the data for each student, a characteristic is compiled, conclusions are drawn, and tasks are set to adjust the individual curriculum for the next year. An information letter is sent to parents (legal representatives), reflecting the development dynamics and assessment of the cooperation of an educational organisation and a family on the issues of raising and educating a child.

Distance learning is not the only form of conducting classes and does not exclude the direct interaction of a student with a teacher in the process of home-based training or attending a comprehensive school. The correlation of distance learning with other forms depends on the specific possibilities of health, the student's social situation, and a territorial location. The authors attribute the following to the parameters of the effectiveness of the distance learning model:

1. Interactivity: distance learning should provide maximum interaction between a student and a teacher. Highly effective feedback allows tracking progress from not knowing to knowledge. It can be operational, deferred in the form of an external assessment. 
2. Individualisation of training improves the perception of educational material, increases educational motivation, and the formation of practical skills of training and self-education.

\section{Participation in design and research activities.}

Distance learning involves drawing up individual calendar-thematic planning for each student and conducting distance lessons, which take place according to a pre-compiled schedule. The distance lesson takes place as follows: 1) a teacher is in the distance shell, namely in a class, according to the materials of which a lesson is planned; 2) for operational communication with a student, chat, Skype, internal messaging are used; 3) a teacher initiates contact with a child at the beginning of a lesson, announces a purpose and objectives of a lesson, a plan, invites a student to communicate in programs for online interaction; 4) throughout a lesson, regardless of the chosen form of its conduct, a teacher is in a classroom and is available in a program for operational online interaction (chat, Skype); 5) in the absence of a student in a distance shell, a teacher tries to find out the reason for his absence (individual child forum, phone call). A prerequisite for organising distance learning is the active inclusion of students' parents in the activities of. This feature is implemented through coordination with parents of an individual educational route and a unified education program, and training parents in information and communication technologies. At the beginning of the training, a child needs to be helped to master the computer's work to carry out educational activities and master the skills of working in the electronic shell. Hence, parents need to be interested in lessons in remote mode. Education for all is an integral part of a prosperous society. Such education can be implemented using distance learning, it is only necessary to create the most accessible and effective educational space, the organisation of which will take into account the individual characteristics of students and include not only students but also teachers, parents, and assisting professionals.

\section{DISCUSSION}

To implement a distance course, a teacher needs to form the structure of a standard distance course, in a model of which the following units should be present: the unit of the course content (lectures, instructions for students, sources, glossaries); the control unit (current - test work, web quest, resume, article, situational analysis, test, online consultations, final - round table, project work, distance lesson); the organisational unit (dating forum, educational process documentation, current announcements); the unit of communication tools for individual and group training (forum, email, $I C Q$, wiki-wiki, video conferencing, voice chat, blogs, network community sites, chat, mailing list, etc.); the summarising unit (reflection after studying each module and at the end of a course). Units 1 and 2 represent the methodological work before a course (preparation), units 3 and $4-$ a course, and unit 5 - results $[12,13]$.

To implement distance learning, a teacher must know the educational segment of the Internet, navigate the pedagogical network communities, have the skills to conduct the educational process using information and communication technologies, know and be able to use pedagogical distance learning technologies, be able to teach his subject in any form using any means communication [14, 15].

In the context of teaching using distance educational technologies, the following functions of working with persons with disabilities are assigned to a teacher: organisation of educational and research activities using ICT; organisation of work on the creation of telecommunication projects; individual and group training in various models; development of various didactic models based on a network resource; preparation of preventive tasks for a lesson; interaction with a curator and psychologist; organisation of work in small groups of cooperation; participation in pedagogical newsgroups and seminars; analysis and evaluation of student work; participation in the moderation process; online and offline consultations; conducting Internet discussions and Internet conferences [16].

In accordance with the designated functions, a distance pedagogue should have competencies that can be attributed to three groups:

- competencies in the field of psychology (knowledge of the psychological characteristics of communication in a virtual environment, the characteristics of age-related changes in the perception of virtual communication, the principles of distance learning for children, adolescents, adults);

- competencies in the field of pedagogy: pedagogical technologies of distance learning (methods and technologies corresponding to them); 
- competencies in the field of information technology: fluency in the means of communication on the Internet, the desire to learn new tools, network services, mastery of constantly improving tools.

According to S.V. Alekhina, the personality of $\phi$ teacher is of particular importance in the implementation of distance learning in inclusive education. After all, only love for children, for their work, will help create such an interaction in which the individual capabilities of each child will be taken into account, the time in the lesson will be correctly distributed, and it will be possible to trace the development of an individual child and his personal progress. It is through such interaction that the child learns the world: phenomena, processes, patterns, will be able to navigate in the surrounding reality $[17,18]$.

Currently, there are a huge number of principles of distance learning, but the authors agree with $\mathrm{P}$. V. Zakotnova, who identified the following principles of distance learning [19]:

1. The principle of activity and independence of students as the main subjects of education, implying the presence of an internal motive for education.

2. The principle of cooperative activity, providing for the joint activity of a student with a teacher in the planning, implementation, evaluation, and correction of a learning process. The active side of distance learning should prevail over the information one, which means that, firstly, the content of educational materials is built around the main types of activities of a student; secondly, the organisation of a learning process is based on students reflecting on their own experience and learning outcomes.

3. The principle of reliance on student's life experience is used as one of the sources of training.

4. The individualisation of training. In accordance with this principle, everyone chooses his own training program taking into account educational needs and goals, experience, psychological and physical capabilities.

5. The principle of updating learning outcomes, involving the immediate application in practice of acquired knowledge.
6. The principle of reflexivity. It implies understanding students of all the parameters of the learning process, methods of activity, and, most importantly, their own changes.

7. The principle of modular-block organisation of the content of education and activities of students.

8. The problematic, dialogue character and practical orientation of the content and nature of interaction in the educational process.

9. Consistency and integrity of training. This principle provides for the conformity of content, methods, teaching aids, and activities.

10. The principle of a combination of types of communication. On the one hand, the implementation of certain communications via the Internet (computer conferences, email) can remove some psychological barriers and contribute to the student's liberation; on the other hand, it is only in direct communication possible to track the dynamics of changes in the needs of a student and a trajectory of his development, to conduct an examination of creative results of activities, solve unusual situations, and promote the development of creative, communicative and reflective abilities.

According to E.S. Polat, success and quality of the implementation of distance learning to a greater extent depend on the effective organisation and pedagogical quality of the materials used, the pedagogical guidance, and the skill of teachers involved in this process. Means of distance learning can be: textbooks and teaching aids on paper; textbooks and teaching aids on CDs; audio training materials; video educational materials; simulators with remote access; computer training systems in hypertext and multimedia versions [20].

In the authors' opinion, the effectiveness of distance learning depends on four components:

1) the effective interaction of a teacher and a student despite the fact that they are physically separated by distance;

2) pedagogical technologies used for this;

3) the effectiveness of the developed teaching materials and methods for their delivery; 
4) feedback effectiveness.

A prerequisite for organising distance learning is the active inclusion of students in parents' activities (legal representatives). This feature is realised through coordination with parents of an individual educational route and a unified education program, and training parents in information and communication technologies. At the beginning of the training, a child must be helped to master a computer to carry out educational activities; therefore, the interest of parents (legal representatives) in the lessons in the remote mode is necessary.

The main goals of distance learning can be formulated as: the acquisition by students of the opportunity to improve, replenish their knowledge in various fields in the context of existing distance learning programs; the opportunity to obtain a certificate of education, professional, qualification degree, as well as high-quality education in various areas of educational programs. The organisation of the educational process using distance technologies implies high independence of students, which in turn complicates this process for most categories of people with disabilities. However, the transition to education, where a student himself is the first and foremost, leads to the development of self-reliance skills and expands the child's capabilities. In addition, it should be noted that new technical and technological means of network communications can provide fundamentally new methodological opportunities for distance learning of children with special needs precisely in the framework of general education.

When organising distance learning for children with special needs, one should keep in mind the difficulties that arise, both in the work of a teacher-tutor and a student. Among them, one can single out the possibility of limiting the abilities for creative development of children, informational and illustrative possibilities of a teacher in the educational process, contributing to his direct emotional impact on a child with disabilities in order to support his interest and educational motivation. Also, difficulties experienced by children with disabilities in the learning process can be caused by both shortcomings in mental activity, the emotionalvolitional sphere (self-regulation and self-control), a low level of educational motivation, and general cognitive passivity, as well as the underdevelopment of individual mental processes. This, in turn, can manifest itself in the form of insufficient coordination of movements, motor disinhibition, low working capacity, limited stock of knowledge and ideas about the surrounding reality, lack of formation of the operational components of educational and cognitive activity. In addition to the above, it should be noted that modern information technologies require a significant increase in the degree and level of mastery of special skills, and, accordingly, knowledge and ways of working with information, owning various types of reading it, working with electronic directories and dictionaries.

In this connection, the distance learning model should: flexibly combine the independent cognitive activity of students with various sources of information, educational materials; combine operational and systematic interaction with a teacher, tutor, as well as group work according to the type of training in cooperation with participants in the educational process, using a variety of methods; provide for joint telecommunication projects, organising discussions, group presentations, and individual presentations during electronic teleconferences, exchanging information and opinions. Such is the model the authors developed.

\section{CONCLUSIONS}

The introduction of distance learning as an innovative technology has revealed several advantages: access for children with disabilities to educational and other information resources; socialisation and integration of children with disabilities in society into a wide audience of students; taking into account the individual characteristics of children; interactivity of training; spatial and temporal infinity of learning; continuous technological improvement; quality education for children with disabilities; support for families of children with disabilities. Meanwhile, certain difficulties in the implementation of distance learning for children are associated with high material costs on the technical basis of education; pedagogical and methodological readiness of teachers; technological readiness of participants in the educational process; the willingness of participants in the educational process to communicate online.

One of the main advantages of using computerbased teaching aids in the education of children with disabilities is their great ability to visualise the educational material provided. Multimedia technology enriches the learning process, allows making education more effective, and also contributes to the creative development of students. The introduction of distance learning technologies in the educational process leads 
to the emergence of new opportunities for the implementation of problem-search and design activities of students. The search for the most optimal ways, means, methods for the successful adaptation and integration of children with disabilities in society is the task of everyone. After all, to help fill the black and white world of a "special child" with bright and light tones is possible only by joint efforts.

\section{ACKNOWLEDGEMENT}

None.

\section{REFERENCES}

[1] Choi HJ, Smith RA. Members, isolates, and liaisons: Metaanalysis of adolescents' network positions and their smoking behavior. Substance Use and Misuse 2013; 48(8): 612-22. https://doi.org/10.3109/10826084.2013.800111

[2] Balázs MA, Pikó B. Serdülokori alkoholfogyasztást befolyásoló tényezok: a szociális háló és a barátok szerepe. Mentalhigiene Es Pszichoszomatika 2013: 14(1): 25-44.

[3] Montgomery SC, Donnelly M, Bhatnagar P, Carlin A, Kee F, Hunter RF. Peer social network processes and adolescent health behaviors: A systematic review. Preventive Medicine 2020; 130: article number 105900.

https://doi.org/10.1016/j.ypmed.2019.105900

[4] Bryan B. Paternal incarceration and adolescent social network disadvantage. Demography 2017; 54(4): 1477-1501. https://doi.org/10.1007/s13524-017-0589-8

[5] Cochran M, Bø I. The social networks, family involvement, and pro- and antisocial behavior of adolescent males in Norway. Journal of Youth and Adolescence 1988; 18(4): 37798. https://doi.org/10.1007/BF02139256

[6] Gentina E, Bonsu SK. Peer network position and shopping behavior among adolescents. Journal of Retailing and Consumer Services 2013; 20(1): 87-93. https://doi.org/10.1016/j.jretconser.2012.10.009

[7] Browning CR, Soller B, Jackson AL. Neighborhoods and adolescent health-risk behavior: An ecological network approach. Social Science and Medicine 2015; 125: 163-72. https://doi.org/10.1016/j.socscimed.2014.06.028

[8] Prochnow T, Delgado H, Patterson MS, Meyer MRU. Social network analysis in child and adolescent physical activity research: A systematic literature review. Journal of Physical Activity and Health 2020; 17(2): 250-60. https://doi.org/10.1123/jpah.2019-0350

[9] Jacobs W, Goodson P, Barry AE, McLeroy KR. The role of gender in adolescents' social networks and alcohol, tobacco, and drug use: A systematic review. Journal of School Health 2016; 86(5): 322-33.

https://doi.org/10.1111/josh.12381
[10] Shin H. Friendship dynamics of adolescent aggression, prosocial behavior, and social status: The moderating role of gender. Journal of Youth and Adolescence 2017; 46(11): 2305-20.

https://doi.org/10.1007/s10964-017-0702-8

[11] Jacobs W, Goodson P, Barry AE, McLeroy KR, McKyer ELJ, Valente TW. Adolescent social networks and alcohol use: Variability by gender and type. Substance Use and Misuse 2017; 52(4): 477-87. https://doi.org/10.1080/10826084.2016.1245333

[12] Jeon KC, Goodson P. US adolescents' friendship networks and health risk behaviors: A systematic review of studies using social network analysis and Add Health data. PeerJ 2015; 2015(6): article number 26157622. https://doi.org/10.7717/peeri.1052

[13] Li X, Kawachi I, Buxton OM, Haneuse S, Onnela J-P. Socia network analysis of group position, popularity, and sleep behaviors among U.S. adolescents. Social Science and Medicine 2019; 232: 417-26. https://doi.org/10.1016/j.socscimed.2019.05.026

[14] Van Den Bos W, Crone EA, Meuwese R, Güroğlu B. Socia network cohesion in school classes promotes prosocial behavior. PLoS ONE 2018; 13(4): Article number e0194656. https://doi.org/10.1371/journal.pone.0194656

[15] Mason MJ, Valente TW, Coatsworth JD, Mennis J, Lawrence F, Zelenak P. Place-based social network quality and correlates of substance use among urban adolescents. Journal of Adolescence 2010; 33(3): 419-27. https://doi.org/10.1016/j.adolescence.2009.07.006

[16] Arias Ramos N, Calvo Sánchez MD, Fernández-Villa $T$, Ovalle Perandones MA, Fernández García D, MarquésSánchez P. Social exclusion of the adolescent with overweight: study of sociocentric social networks in the classroom. Pediatric Obesity 2018; 13(10): 614-20. https://doi.org/10.1111/ijpo.12396

[17] Mennis J, Mason MJ. People, places, and adolescent substance use: Integrating activity space and social network data for analysing health behavior. Annals of the Association of American Geographers 2011; 101(2): 272-91. https://doi.org/10.1080/00045608.2010.534712

[18] Wölfer R, Cortina KS, Baumert J. Embeddedness and empathy: How the social network shapes adolescents' social understanding. Journal of Adolescence 2012; 35(5): 1295305. https://doi.org/10.1016/j.adolescence.2012.04.015

[19] Seo D-C, Huang Y. Systematic review of social network analysis in adolescent cigarette smoking behavior. Journal of School Health 2012; 82(1): 21-7. https://doi.org/10.1111/j.1746-1561.2011.00663.x

[20] Steijn WMP. A developmental perspective regarding the behaviour of adolescents, young adults, and adults on social network sites. Cyberpsychology 2014; 8(2): article number 5. https://doi.org/10.5817/CP2014-2-5

\section{DOI: https://doi.org/10.6000/2292-2598.2020.08.03.3}

(c) 2020 Gerasimova et al.; Licensee Lifescience Global.

This is an open access article licensed under the terms of the Creative Commons Attribution Non-Commercial License (http://creativecommons.org/licenses/by-nc/3.0/) which permits unrestricted, non-commercial use, distribution and reproduction in any medium, provided the work is properly cited. 